\title{
Base para una teoría semántico/pragmática de la información genética* ${ }^{* \dagger}$
}

Basis for a Semantic/Pragmatic Theory of Genetic Information

\author{
João Queiroz $z^{\ddagger}$ \\ Claus Emmeche ${ }^{\S}$ \\ Charbel El-Hani
}

\begin{abstract}
Resumen
En este artículo presentamos algunas consideraciones sobre una interpretación semiótica de los sistemas de información genética, como una base para la elucidación del concepto de información, que carece en biología de una teoría que posibilite la comprensión de sus aspectos semánticos y pragmáticos. La teoría de los signos de Peirce incluye conceptos que ayudan a entender como genes en el DNA pueden tener una significación biológica para la célula. Con base en estos conceptos, hacemos un análisis semiótico de los sistemas de información genética.
\end{abstract}

Palabras clave: biosemiótica - gen - información - Peirce

\begin{abstract}
In this contribution, we present some considerations on a semiotic interpretation of genetic information systems, as a basis for the explication of the concept of information, which in biology lacks a theory that allows the understanding of its semantic and pragmatic aspects. Peirce's theory of signs includes concepts that help to understand how genes in DNA can have biological significance for the cell. Based on these concepts, we make a semiotic analysis of genetic information systems.
\end{abstract}

Keywords: biosemiotics - gene - information - Peirce

* Recibido: 3 de enero de 2016. Aceptado con revisiones: 8 de marzo de 2016.

† Agradecemos a Lucía Naser por su traducción y revisión. J.Q. y C.E.H. agradecen a la Fundação de Amparo à Pesquisa do Estado da Bahía (FAPESB), y al Conselho Nacional de Desenvolvimento Científico e Tecnológico (CNPq), por los apoyos recibidos. CNEH agradece a CNPq (proceso número 465767/2014-1) y CAPES ( proceso número 23038.000776/2017-54) por su apoyo a INCT INTREE, y a CNPq por apoyo en la forma de beca de productividad en la investigación (proceso número 303011/2017-3).

* Universidad Federal de Juiz de Fora (UFJF), Brasil. Para contactar al autor, por favor, escribir a: queirozj@gmail.com.

\$ Universidad de Copenhague (KU), Dinamarca. Para contactar al autor, por favor, escribir a: claus.emmeche@gmail.com.

- Universidad Federal de Bahia (UFBA), Brasil. Para contactar al autor, por favor, escribir a: charbel.elhani@gmail.com. Metatheoria 7(1)(2016): 31-48. ISSN 1853-2322. eISSN 1853-2330.

(c) Editorial de la Universidad Nacional de Tres de Febrero. Publicado en la República Argentina. 


\section{Introducción}

La Biosemiótica es un campo en desarrollo que investiga procesos semióticos en los sistemas vivos en un intento de combinar los hallazgos de las ciencias biológicas y de la semiótica. "Procesos semióticos" dicen respecto de aquello a lo que los biólogos se han referido típicamente como "señales" y "procesamiento de información" en biosistemas, aunque aquí estos procesos serán comprendidos bajo la noción mas general de semiosis, esto es, la acción de signos. De esta forma, la biosemiótica puede ser vista como biología interpretada como un estudio de los sistemas de interpretación de signos en seres vivos. En otras palabras, la Biosemiótica es un campo de estudio que investiga procesos semióticos (significado, significación, comunicación y la formación de hábitos en sistemas vivos) y las precondiciones fisicoquímicas para la acción de los signos.

Tratar la Biosemiótica como biología interpretada como estudio de sistemas de signos en seres vivos es enfatizar no solo una importante relación inter-teórica entre biología tal como la conocemos (como campo de investigación) y semiótica (el estudio de signos), sino también, y en primer lugar, un modo de comprender la vida en el que este fenómeno es considerado no únicamente desde la perspectiva de la física y la química, sino también desde un análisis de los sistemas vivos que enfatiza el rol de los signos interpretados por aquellos sistemas en una variedad de formas, como por ejemplo las moléculas que tienen un papel en procesos informacionales. En este sentido, la biosemiótica da por sentado y preserva la complejidad de los procesos vivos revelada por los campos ya existentes de la biología -de la biología molecular a la ciencia cognitiva y los estudios del comportamiento. Sin embargo, la biosemiótica intenta integrar hallazgos aislados de las diversas disciplinas de la biología (incluyendo la biología evolutiva) por medio de una interpretación de fenómenos centrales del mundo vivo desde una perspectiva teórica de los signos, incluyendo la generación de función y significación en los sistemas vivos.

Una de las características centrales de los sistemas vivos es el carácter altamente organizado de sus procesos físicos y químicos, basado en parte, en procesos informacionales. Distinguidos biólogos, tales como Ernst Mayr, han observado estos aspectos informacionales como una de las características emergentes de la vida, más precisamente como un conjunto de procesos que diferencian la vida de cualquier otra cosa en el mundo físico (Mayr 1982). Las tradiciones reduccionistas y mecanicistas en biología (y en filosofía de la biología) han abordado estos procesos como puramente físicos y relacionados únicamente con la así llamada "causalidad eficiente". La biosemiótica es una tentativa de utilizar los conceptos de la semiótica (en el sentido de Charles Sanders Peirce, el amplio estudio lógico y científico de la acción dinámica de los signos (ver CP 5.484). ${ }^{1}$ La Biosemiótica ve la evolución molecular de la vida y la evolución de los sistemas semióticos como dos aspectos del mismo proceso. Debido en parte al éxito de la biología molecular, el enfoque científico del origen y evolución de la vida ha dado cuenta de modo muy satisfactorio de algunos aspectos del proceso en su totalidad, pero ha pasado por alto aspectos cualitativos inherentes a la acción de los signos, resultando en un abordaje reduccionista de la causalidad. Los sistemas vivos complejos y autoorganizados también son gobernados por causalidad formal y final - "causalidad formal" en el sentido de "causalidad descendiente" de la totalidad de una estructura (tal como el organismo) hacia sus moléculas individuales, limitando su acción, pero también atribuyéndoles significados funcionales dentro del metabolismo como un todo (Emmeche, Køppe \& Stjernfelt 2000, El-Hani \& Emmeche 2000); y “causalidad final” en el sentido de

\footnotetext{
${ }^{1}$ Los trabajos de Peirce son referidos como CP (seguido por volumen y número de párrafo) para citas de The Collected Papers of Charles S. Peirce (Peirce, 1866-1913); EP (seguido por volumen y número de página) para citas de The Essential Peirce (Peirce 1893-1913); MS (seguido por número del manuscrito) para citas de The Annotated Catalogue of the Papers of Charles S. Peirce; SS (seguido por número de página) para citas de Semiotic and Significs: The Correspondence between Charles $S$. Peirce and Victoria Lady Welby; y W (seguido por número de página) para cotas de Writings of Charles S. Peirce: A Chronological Edition.
} 
la tendencia a adquirir hábitos y generar futuros interpretantes ${ }^{2}$ de las acciones presentes de los signos. ${ }^{3}$ Aquí, la biosemiótica aprovecha algunas ideas provenientes de campos como la teoría de sistemas, la biología teórica y el estudio de sistemas complejos auto-organizados.

A continuación, ofreceremos una introducción a este campo mediante la descripción de un modelo del sistema de signos genéticos de la célula. Nuestra discusión teórica se referirá, en particular, al concepto semiótico de la información.

\section{Una base teórica para un enfoque biosemiótico de los sistemas vivos}

El concepto de información y otros conceptos relacionados con ésta en biología (señalización, código, trascripción, traducción, etc.), no sólo deben considerarse seriamente, sino que también deben ser clarificados mediante el empleo de herramientas conceptuales adecuadas. El uso de conceptos y teorías semióticas para interpretar el lenguaje de la información puede contribuir significativamente a una formulación precisa y coherente del conjunto de nociones relacionadas al concepto de información en biología. Un tratamiento semiótico de la información biológica también puede ayudar a clarificar algunos malentendidos sobre el papel de los genes en los sistemas biológicos, evitando conceptos muy criticados tales como "planos" y "programas" genéticos (ver, e.g., Oyama [1985] 2000, Nijhout 1990, Sarkar 1996, El-Hani 1997, Keller 2000), al tiempo en que preserva el concepto de "proceso informacional", aunque reinterpretado radicalmente. También brinda apoyo a la idea, ampliamente aceptada hoy día, de que hay más información en los sistemas vivos que simplemente información genética.

Nuestro propósito principal aquí es demostrar cómo algunos de los conceptos centrales de la semiótica de Peirce pueden ser aplicados a modelos de procesos informacionales en sistemas biológicos. Nos referiremos específicamente a trabajos de semiótica aplicada en los que hemos desarrollado el análisis de la información genética y los sistemas de signos basándonos en la teoría de los signos de Peirce (Queiroz, Emmeche \& El-Hani 2005, El-Hani, Queiroz \& Emmeche 2006, ElHani, Arnellos \& Queiroz 2007). En otros artículos, presentamos el análisis semiótico de procesos de comunicación en animales no humanos (Queiroz \& Ribeiro 2002, Ribeiro et al. 2007). Como primera etapa de nuestra argumentación discutiremos el estatus del lenguaje de la información en biología.

\subsection{El lenguaje de la información en biología}

Durante las décadas de 1950 y 1960, la genética, la citología y la biología molecular han sido inundadas por términos importados de la teoría de la información. La influencia de este 'lenguaje de la información' (en la literatura anglófona generalmente designada como 'information talk'), o 'lenguaje cuasi-semiótico', aún impregna estos campos, incluyendo términos ampliamente utilizados tales como 'código genético', 'ARN mensajero', 'trascripción', 'traducción', 'transducción', 'reconocimiento', 'información genética', 'señales químicas', 'señalización celular', etc. Pero, así como el concepto de información y su plétora de conceptos asociados se introdujeron en la biología, también lo hicieron varios problemas que la tradición de la biología no estaba preparada para enfrentar. En lugar de profundizar en el debate acerca de los problemas relacionados con el lenguaje de la información, la tendencia de las ciencias biológicas fue la de tratar la 'información' como mera información secuencial en el ADN o las proteínas.

No obstante, algunos investigadores consideran al lenguaje de la información como inadecuada y tan sólo metafórica, expresando un escepticismo sobre el uso del término 'información' y sus derivados en biología (Stuart 1985, Sarkar 1996). Discordamos con esta posición, afirmando en cambio que la

\footnotetext{
2 'Interpretante' es el efecto producido por el signo. Más adelante (sección 2.3), el término es definido en conexión con la noción de Peirce de un signo como una relación triádica.

3 Si se prefiere no utilizar la categoría de causalidad para explicar estos aspectos de los sistemas vivos, podría hablarse de determinación formal y final, en un marco que reconoce la existencia de otros tipos de determinación, además de la causal, en sistemas naturales (El-Hani \& Queiroz 2005).
} 
noción de información y otras ideas relacionadas captan algunas características propias de los sistemas biológicos y de los procesos que de otra forma podrían ser tratados descuidadamente. Los conceptos de 'código', 'información', 'signos', 'mensaje', 'señalización', entre otros, pueden considerarse como necesarios para comprender la organización de las relaciones en los seres vivos, de modo de esclarecer que lo que ocurre en estos seres es mucho más que simple química. Bray, por ejemplo, ha argumentado que "los organismos pueden considerarse como complejos sistemas procesadores de información, para los cuales el análisis molecular puede no ser suficiente" (citado por Williams 1997, pp. 476-477).

Ideker, Galitski y Hood (2001), en un artículo sobre la biología de sistemas, sostienen que la biología es una ciencia de la información. En efecto, desde las primeras aplicaciones de modelos cibernéticos a las ciencias de la vida, la biología ha sido crecientemente conceptualizada como una ciencia de la comunicación y la información (por ejemplo, Keller 2005), aunque en muchos casos no está claro qué es lo que se entiende por 'información' en biología (Emmeche 1994, Griffiths 2001, Jablonka 2002, Jablonka \& Lamb 2005).

No es de extrañar que los biólogos hallan sentido la necesidad de hablar de información al profundizar cada vez más en la micro-estructura molecular de los sistemas vivos. Los científicos de la vida necesitaban un modo de transmitir la idea que, a pesar de que todos los procesos celulares son procesos físico-químicos, algo más que pura física y química tiene lugar en ellos. En verdad se trata de procesos fisicoquímicos organizados, imbricados de un modo complejo en redes de comunicación e información. En este contexto, es muy difícil ver cuál sería la verdadera ventaja de descartar el lenguaje de la información de la biología, en lugar de hacerlo más preciso y estudiar sus consecuencias con mayor profundidad. Por lo tanto, el problema no es deshacerse del lenguaje de la información, sino clarificar este concepto mediante el uso de un marco teórico adecuado.

Como resume Griffiths, 'información genética' es una metáfora en búsqueda de una teoría (Griffiths 2001). Creemos que, en términos generales, esto se aplica al lenguaje de la información en biología. Una posibilidad para la construcción de una teoría de la información en biología es apoyarse en la teoría matemática de la comunicación. Esta teoría nos permite definir la cantidad de información como la medida de la probabilidad de selección de un mensaje particular entre el conjunto de todos los mensajes posibles.

La medida probabilística de la información proporcionada por esta teoría es no-semántica, indiferente al significado (Shannon \& Weaver 1949, Cover \& Thomas 1999, Jablonka 2002). Es cierto que este concepto de información desprovista de significado puede ser útil para varios propósitos en la investigación biológica (Adami 2004). Sin embargo, se ha argumentado que un entendimiento nosemántico (y cuantitativo) de la información no es suficiente para elaborar una teoría de la información biológica, y debería ser complementada por un abordaje semántico-pragmático (y más cualitativo). Jablonka (2002), por ejemplo, menciona el caso de una secuencia de ADN que codifica una enzima funcional y una secuencia con la misma extensión que codifica un polipéptido completamente no funcional (que inclusive puede tener solo un nucleótido diferente). Ambas secuencias contendrán, de acuerdo con la medida no-semántica anteriormente mencionada, la misma cantidad de información. Sin embargo, es evidente que estos dos mensajes no significan lo mismo para la célula. Esto sugiere la inadecuación de la teoría matemática de la comunicación en el abordaje de todos los problemas planteados por el lenguaje de la información en biología, y también indica la necesidad de un tratamiento de la información en biología que incluya una dimensión semántica y una dimensión pragmática. $\mathrm{O}$, para expresarlo de otro modo, una teoría de la información en biología también debería tener en cuenta el significado de los 'mensajes' y el contexto en el cual éstos son interpretados. Aquí utilizamos conceptos semióticos para contribuir para la construcción de un enfoque semántico y pragmático de la información biológica. En particular, proponemos un modelo de información como semiosis, basado en la teoría pragmática de los signos de Peirce.

\subsection{Semiótica peirceana: una breve introducción}

Peirce es a menudo considerado el fundador de la semiótica moderna (Weiss \& Burks 1945, p. 386). Semiótica fue definida por Peirce (CP 5.484) como "la doctrina de la naturaleza esencial y fundamental 
de todas las variedades de semiosis posibles". En otras palabras, la semiótica describe y analiza la estructura de los procesos semióticos independientemente de sus bases materiales, o de las condiciones en que pueden observarse en el interior de las células (cytosemiosis), entre tejidos y poblaciones de células (semiosis vegetativa), en la comunicación animal (zoosemiosis) o, en actividades humanas típicas (producción de notaciones, meta-representaciones, etc.). En otras palabras, el concepto peirceano de la semiótica implica una teoría del signo en su sentido más general. Peirce concibió la semiótica general como una ciencia formal con características similares a las matemáticas (CP 2.227). Sin embargo, a diferencia de aquella, la semiótica encuentra los objetos de su investigación en el ambiente concreto, natural de los signos -y en la "experiencia humana ordinaria" (CP 1.241).

La semiótica especulativa se subdivide en gramática especulativa, lógica crítica, y retórica especulativa (CP 2.229). La primera división de esta ciencia es lo que nos interesa aquí. Su objetivo es examinar "la fisiología de signos de todo tipo" (CP 2.83), es decir, la naturaleza concreta de los signos a medida que éstos emergen y se desarrollan, y las condiciones que determinan su posterior desarrollo, naturaleza e interpretación. Se trata de la rama que investiga: (i) las condiciones a las que todo y cualquier tipo de signo debe ser sometido, (ii) el signo en sí mismo, y (iii) su verdadera naturaleza (CP 1.444). Como parte de sus tareas, la gramática especulativa trabaja sobre la "clasificación de los signos" o, en otras palabras, la diversidad de tipos de signos y el modo en que éstos se combinan entre sí para generar complejos procesos semióticos.

Para Houser, "el lógico que se concentra en la gramática especulativa investiga las relaciones de representación (signos), tiene por objeto elaborar las condiciones necesarias y suficientes para la representación, y clasifica los diferentes tipos de representación posibles” (Houser 1997, p. 9). Entre 1867 y 1911, Peirce desarrolló un modelo de signos como procesos, acciones, relaciones, y también elaboró clasificaciones de los signos con el fin de describir los diferentes tipos de procesos semióticos.

El modelo pragmático del significado como 'acción de los signos' (semiosis) propuesto por Peirce, ha tenido un profundo impacto en la filosofía, la psicología, la biología teórica, y las ciencias cognitivas (ver Freeman 1983, Fetzer 1997, Colapietro 1989, Tiercelin 1995, Hoffmeyer 1996, Deacon 1997, Freadman 2004, Hookway 2002). Sobre todo, cabe destacar que la semiótica de Peirce se basa en una lista de categorías -Primeridad, Segundidad, Terceridad- que corresponde a un exhaustivo sistema de tipos de relaciones organizadas jerárquicamente (Houser 1997). Este sistema constituye la base formal de la filosofía de Peirce (Parker 1998) y su modelo de acción semiótica (Murphey 1993, pp. 303-306). En resumen, las categorías se pueden definir de la siguiente manera: (1) Primeridad: lo que una cosa es sin referencia a ninguna otra cosa; (2) Segundidad: lo que una cosa es en relación con otra cosa, pero sin relación con una tercera entidad; (3) Terceridad: lo que una cosa es la medida en que es capaz de poner a una segunda entidad en relación con una primera de la misma manera que establece en sí misma una relación con la primera y la segunda entidad. La Primeridad es la categoría de la vaguedad y de la novedad: "la Primeridad es el modo de ser que consiste en el ser del objeto positivamente como este es, independientemente de cualquier otra cosa. Esto sólo puede ser una posibilidad" (CP 1.25). La Segundidad es la categoría de la reacción, la oposición, y la diferenciación: "en términos generales la verdadera Segundidad consiste en una cosa actuando sobre otra, -acción bruta [...]. Considero la idea de cualquier relación diádica que no implique ningún tercero como una idea de Segundidad" (CP 8.330). Por último, la Terceridad es la categoría de la mediación, el hábito, la generalidad, la evolución y la conceptualización (CP 1.340). ${ }^{4}$

\subsection{Semiosis y procesamiento de información}

Según Peirce, cualquier descripción de la semiosis debe tratarse necesariamente como una relación constituida por tres términos irreductiblemente conectados: signo-objeto-interpretante (CP 2.171, CP 2.274) -en este trabajo nos referiremos a estos términos de la relación triádica como S, O e I.

Para Peirce, un signo es algo que representa algo distinto de sí mismo. Peirce definió los signos de varias maneras diferentes (Marty \& Lang 1997), pero aquí nos referiremos tan solo a algunas

\footnotetext{
${ }^{4}$ Para más discusión de las categorías, ver Hookway (1985), Murphey (1993), Potter (1997).
} 
definiciones básicas, que serán útiles en nuestro trabajo. Él concibió el signo como "un Primero que se sitúa en una auténtica relación triádica con un Segundo, llamado su Objeto, de manera que sea capaz de determinar un Tercero, llamado su Interpretante "(CP 2.274; ver también CP 2.303, 2.92, 1.541).

La relación triádica entre $\mathrm{S}, \mathrm{O}$ e I es considerada por Peirce como irreducible en el sentido de que no puede ser descompuesta en ninguna relación más simple. En consecuencia, el término 'signo' fue utilizado por Peirce para designar el proceso triádico irreducible entre $\mathrm{S}, \mathrm{O}$ e I, aunque también lo utilizó para referirse al primer término de la tríada. Algunos comentaristas han propuesto que se debe distinguir entre el 'signo en sentido estricto' (representamen, o vehículo del signo), cuando se refiere al primer término de la tríada, y el 'signo en sentido amplio' (o proceso sígnico, signo como un todo) (por ejemplo, Johansen 1993, p. 62). Los signos, concebidos en sentido amplio, nunca se encuentran solos.

En las definiciones de signo de Peirce, encontramos varias pistas para entender cómo actúan los signos. Cualquier signo es algo que representa otra cosa, su objeto, de tal forma que termina por producir una tercera entidad relacional, un interpretante, que es el efecto que un signo produce en un intérprete (que es, en el contexto de la biosemiótica, un biosistema, tal como una célula o un organismo). En muchos procesos biológicos informacionales, la interpretación de signos resulta en un nuevo signo en el intérprete, que se refiere al mismo objeto al que el signo anterior se refería, o en última instancia, a una acción que puede dar lugar a la conclusión de un proceso informacional. Que el interpretante es a menudo otro signo, creado por la acción de un signo anterior, es claro en la siguiente declaración de Peirce: un signo es "cualquier cosa que determina que alguna otra cosa (su interpretante) se refiera a un objeto al que el mismo se refiere (su objeto), del mismo modo, a su vez convirtiéndose el interpretante en un signo, y así sucesivamente, ad infinitum" (CP 2.303). Por consiguiente, es importante tener siempre en cuenta que el interpretante no es necesariamente el producto de un proceso similar al de la 'interpretación' en el sentido en que utilizamos este término para referirnos a los procesos cognitivos humanos. Como fue explicado anteriormente, la característica fundamental del interpretante en muchos procesos biológicos es que se trata de un nuevo signo producido por la acción de un signo anterior, de manera tal que ambos pueden compartir el mismo referente.

Una de las características más notables de la teoría de los signos de Peirce es su compromiso con una filosofía de procesos. Como verdadero process thinker, es bastante natural que Peirce concibiera la semiosis básicamente como un proceso en el cual las tríadas están sistemáticamente vinculadas entre sí, conformando una red (ver Gomes et al. 2007). La teoría de los signos de Peirce presenta una naturaleza notablemente dinámica. Según Merrell (1995, p. 78), "el énfasis de Peirce no descansa sobre el contenido, la esencia, o la sustancia, sino, más bien, sobre la dinámica de las relaciones. Eventos y no cosas, son enfatizados".

Es importante no perder de vista la diferencia entre el intérprete, que es el sistema que interpreta el signo, y el interpretante. El intérprete es descrito por Peirce como una 'cuasi-mente' (CP 4.536), una descripción que exige, para su correcta interpretación, un claro reconocimiento del amplio concepto de 'mente' de Peirce (Ransdell 1977, Santaella-Braga 1994). No es cierto que únicamente seres conscientes puedan ser intérpretes en el marco de la teoría de Peirce. Por el contrario, un mecanismo de trascripción sintetizando ARN a partir de una cadena de ADN o un receptor de membrana reconociendo una determinada hormona pueden considerarse como intérpretes. Una idea básica en el entendimiento semiótico de los sistemas vivos es que estos sistemas son intérpretes de signos, es decir, que responden continuamente a signos seleccionados en su entorno. Un intérprete es cualquier cosa que participa en la realización de un proceso sígnico. De este modo, el intérprete no es necesariamente un ser consciente, ni siquiera un organismo, sino que puede ser una parte o subsistema dentro de un organismo, o un producto concebido por el hombre. Sin embargo, desde que un proceso sígnico es en sí mismo un intérprete, el concepto de intérprete parece ser secundario en la semiótica de Peirce, a pesar de que puede desempeñar un papel heurístico en la construcción de algunos modelos de procesos semióticos. 
Aquí también debemos considerar las distinciones de Peirce referentes a la naturaleza de objetos e interpretantes (para un análisis de estos temas, ver Savan 1987-1988, Liszka 1990, Short 1996). Él distingue entre objetos inmediatos y dinámicos de un signo de la siguiente manera:

Debemos distinguir entre el Objeto Inmediato -es decir, el objeto tal como es representado en el signoy [...] el Objeto Dinámico, que, por la naturaleza de las cosas, el Signo no puede expresar, que sólo puede indicar y dejar al intérprete descubrir mediante experiencia colateral (CP 8.314, énfasis en el original).

Y:

Hemos de distinguir el Objeto Inmediato, que es el Objeto tal como el propio Signo lo representa, y cuyo Ser es, pues, dependiente de su Representación en el Signo, del Objeto Dinámico, que es la Realidad que de algún modo actúa para determinar el Signo para su Representación (CP 4.536).

También debemos considerar su distinción entre tres tipos de interpretantes:

El Interpretante Inmediato es el posible y pertinente efecto inmediato en su primitiva totalidad no analizada [...]. El Interpretante Dinámico es el efecto real producido sobre un determinado intérprete, en una determinada ocasión, en una determinada etapa de su consideración del Signo (MS 339d: 546547, énfasis en el original).

Y:

[...] el Interpretante Final es el resultado Interpretativo al que todo Intérprete está destinado a llegar si el Signo es considerado suficientemente. [...] El Interpretante Final es aquel hacia el cual el actual tiende (Carta a Lady Welby, SS 110-111, 1909).

Consideremos, en primer lugar, la distinción de Peirce entre los objetos inmediatos y dinámicos de un signo. El objeto inmediato de un signo es el objeto tal como dado al signo de forma inmediata, es decir, el objeto dinámico en su forma semiótica disponible. Así, el aspecto del objeto dinámico que es representado por el signo es el objeto inmediato que se refiere, por lo tanto, al objeto dinámico tal como representado por el signo (esto es lo que queremos decir con "disponibilidad semiótica").

Además, el signo no representa al objeto dinámico en su realidad, sino que sólo indica ese objeto. El sistema que es causalmente afectado por el signo (porque él representa alguna otra cosa para ese sistema) debe establecer qué objeto dinámico es indicado por ese signo, a través de procesos que han sido seleccionados favorablemente en la historia evolutiva de ese tipo de sistema. En escala de tiempo ontogenética, el sistema adquirirá su competencia semiótica, es decir, su competencia como intérprete de signos, mediante un proceso de desarrollo.

Peirce define al interpretante dinámico como el efecto real de un signo, mientras que el interpretante inmediato es su 'espectro de interpretabilidad' -la gama de efectos posibles que un signo es capaz de producir (ver Johansen 1993, pp. 166-167). El interpretante dinámico es, por lo tanto, la realización de uno de los posibles efectos incluidos en el interpretante inmediato. En un proceso semiótico, el interpretante final, es a su vez, el estado final de este proceso, entendido como una tendencia que se realiza cuando una determinada cadena de tríadas es disparada, aunque ésta no está determinada de modo inevitable, ya que pueden seguirse otros estados finales a partir del mismo proceso semiótico, como en el caso, por ejemplo, de los errores de interpretación. De cualquier forma, el interpretante final puede verse como una resolución provisional de la inestabilidad involucrada en el proceso semiótico.

Peirce (CP 8.177) escribe que un signo determina un interpretante en alguna Mente 'real' o 'potencial' (en otros pasajes, una 'cuasi-mente'; ver CP 4.536). De hecho, es posible diferenciar entre semiosis 'potencial' y 'efectiva'. La semiosis potencial se define como un proceso estructurado triádicamente que tiene una disposición a tener lugar en cualquier momento dado, es decir, que podría ocurrir bajo las condiciones apropiadas, aunque no esté efectivamente ocurriendo en aquel momento. A su vez, la semiosis efectiva se refiere a un signo que, al ser actualizado, tiene un efecto real sobre el intérprete. 
La semiosis implica necesariamente la producción de cadenas de relaciones triádicas (lo que aquí vamos a abreviar como 'tríadas'), ya que un signo en una determinada tríada conducirá a la producción de un interpretante, que generalmente será, a su vez, un nuevo signo. Por lo tanto, un interpretante es a la vez el tercer término de una tríada anterior y el primer término (signo) de una tríada subsiguiente (Savan 1986. Ver la figura 1). Aquí tenemos una primera transición que responde por el carácter dinámico de la semiosis, a saber, la transición interpretante-signo (I-S). Por esta 'transición' simplemente queremos decir que el mismo elemento que desempeña el papel del interpretante en una tríada jugará el papel de signo en una tríada subsiguiente. Después de todo, desde una perspectiva peirceana, realizar el procesamiento y la interpretación de signos es producir signos adicionales (o, como dice Peirce, signos más desarrollados).

Es importante tener en cuenta que en un sistema físico, químico o biológico particular, los procesos semióticos descritos aquí en términos generales pueden ser realizados a través de diferentes medios físicos, por ejemplo, por medio de cambios en las concentraciones de determinadas sustancias químicas o de procesos de reconocimiento molecular.

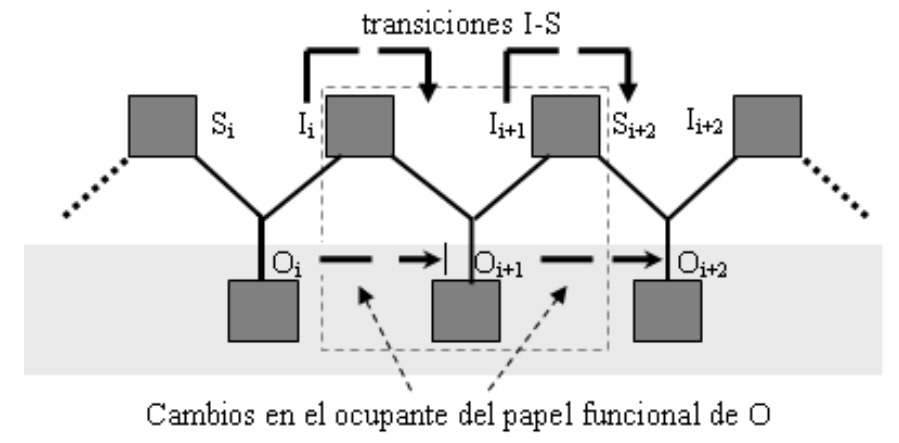

Figura 1: La relación triádica S-O-I forma una cadena de tríadas. El área gris en la parte inferior de la figura muestra que todos los signos en la cadena de tríadas se refieren al mismo objeto dinámico a través de una serie de objetos inmediatos. Las flechas muestran la transición interpretante-signo (I-S) y los cambios en el ocupante del papel funcional del objeto inmediato.

Cuando se da la transición I-S, también se produce un cambio en el ocupante del papel funcional del objeto inmediato (figura 1). Cuando el interpretante se convierte en el signo de una nueva tríada, la relación de referencia hacia el mismo objeto dinámico depende del hecho de que el nuevo ocupante de la función de objeto inmediato represente el mismo aspecto del objeto dinámico que el que el objeto inmediato de la tríada anterior representaba. Debemos destacar, sin embargo, que al referirnos a estos modelos en futuros trabajos, sería recomendable reemplazar el concepto de "referencia" (que constituye un concepto muy debatido y, en ocasiones, poco claro, y que no se halla incluido en la teoría de los signos de Peirce), por un concepto interno al marco teórico de Peirce, a saber, el concepto de 'fundamento' (ground).

Como muestra la figura 1 , en una tríada $i$ un determinado signo $S_{i}$ indica un objeto dinámico representando algún aspecto del mismo, el objeto inmediato $\mathrm{O}_{\mathrm{i}}$. A través de la relación triádica, un interpretante $I_{i}$ es producido en el sistema semiótico. Este interpretante se convierte en el signo de una nueva relación triádica, $\mathrm{S}_{\mathrm{i}+1}$, que ahora indica el mismo objeto dinámico. Él debe indicar este objeto a través de un nuevo objeto inmediato, que corresponde a un aspecto del objeto dinámico representado en el signo. Tenemos ahora un nuevo ocupante de la función de objeto inmediato que representa al mismo aspecto del objeto dinámico que fue representado en el signo anterior, $\mathrm{S}_{\mathrm{i}}$. Es en este sentido que se produce un cambio en el ocupante del papel funcional del objeto inmediato, de $\mathrm{O}_{i}$ en la tríada anterior a $\mathrm{O}_{\mathrm{i}+1}$ en la tríada subsiguiente. A través de la relación triádica, se producirá un interpretante adicional, $\mathrm{I}_{\mathrm{i}+1}$, que a su vez más adelante se transformará en el signo de una nueva tríada, $\mathrm{S}_{\mathrm{i}+2}$, y así sucesivamente, hasta el final de un determinado proceso semiótico. 
Peirce también define un signo como un medio para la comunicación de una forma o hábito incorporado (embodied) en el objeto para el interpretante (De Tienne 2003, Hulswit 2001, Bergman 2000), de modo de restringir al interpretante como signo, o el comportamiento del intérprete:

Un Signo puede definirse como un Medio para la comunicación de una Forma [...]. Como un medio, el Signo se halla esencialmente en una relación triádica, con su Objeto que lo determina, y con su Interpretante al cual él determina. [...] Aquello que es comunicado del Objeto a través del Signo al Interpretante es una Forma; es decir, no es nada que se parezca a un existente, sino que es un poder, es el hecho de que algo podría ocurrir bajo determinadas condiciones (MS 793:1-3. Ver EP 2.544, n. 22, para una versión ligeramente diferente)

¿Qué es una Forma? En los escritos de Peirce hay un movimiento de la 'forma como Primeridad' a la 'forma como Terceridad'. Forma es definida por poseer el "ser del predicado" (EP 2.544) y también es pragmáticamente formulada como una "proposición condicional" que establece que ciertas cosas pueden suceder bajo circunstancias específicas (EP 2.388). No es nada como una "cosa" (De Tienne 2003), sino algo que se halla incorporado (embodied) en el objeto (EP 2.544, n. 22) como un hábito, una "regla de acción" (CP 5.397), una "disposición" (CP 2.170), un "potencial real" (EP 2.388) o, simplemente, la "permanencia de alguna relación" (CP 1.415). En este sentido, es importante destacar que la forma comunicada del objeto al interpretante a través del signo no es la forma particular de un objeto, o algo similar, sino una regularidad, un hábito que permite que un determinado sistema semiótico interprete esa forma como indicativa de una clase particular de entidades, procesos, fenómenos, y, por lo tanto, responda a ella de modo regular. Si esto no fuera así, el sistema semiótico no sería realmente capaz de interpretación.

La comunicación de una forma del objeto al interpretante limita el comportamiento de un intérprete en el sentido de que establece un conjunto limitado de relaciones entre el objeto y el interpretante a través de la mediación del signo. Por lo tanto comprenderemos el 'significado' de un signo como un efecto del signo -concebido como un medio para la comunicación de formas- sobre un intérprete a través de la relación triádica S-O-I. Es así que un proceso de significación puede ser definido como la acción de un signo (semiosis).

En el enfoque de Peirce, la 'información' puede estar fuertemente asociada con los conceptos de significado y semiosis. ${ }^{5}$ Peirce se refería a los signos como "transmisores" (conveyers), como un "medio" (MS 793), como "encarnando significado" (embodying meaning). Así, en su teoría, los conceptos de significado, información y semiosis se interceptan y superponen de modos diferentes (ver Johansen 1993). Peirce definió 'significado' como la consecuencia de la relación triádica entre signo, objeto e interpretante (S-O-I) como una totalidad (EP 2:429), y también en términos de los diferentes correlatos de una tríada -por ejemplo, objeto (MS 11, EP 2:274), interpretante (EP 2:496, EP 2:499, CP 4:536) (ver Fitzgerald 1966, p. 84, Bergman 2000). A su vez, Peirce definió 'información' al menos ordinariamente (CP 2.418), metafísicamente (CP 2.418), como una conexión entre forma y materia, y lógicamente, como el producto de la extensión e intensión de un concepto (W 1.276; ver Debrock 1996).

En el pasaje de MS 793 citado anteriormente, Peirce define un signo tanto como "un Medio para la comunicación de una Forma" así como "una relación triádica, con su Objeto, que lo determina y con su Interpretante al que él determina." Si consideramos ambas definiciones de signo, entonces podemos afirmar que la semiosis es un proceso triádico de comunicación de una forma del objeto al interpretante a través de la mediación del signo. Y también podemos estipular que en el marco de la teoría de Peirce, semiosis es información. Por esta razón, nos referimos sistemáticamente a información como la comunicación de una forma de $\mathrm{O}$ a I a través de S (Queiroz, Emmeche \& El-Hani 2005, ElHani, Queiroz \& Emmeche 2006, Queiroz \& El-Hani 2006a, b).

De acuerdo con nuestra interpretación de las ideas de Peirce, la información tiene la naturaleza de un proceso: es un proceso de comunicación de una forma al Interpretante y opera como una influencia

\footnotetext{
5 También con el concepto de experiencia (CP 1.537).
} 
restrictiva sobre posibles patrones de comportamiento interpretativo. Al aplicar este enfoque semiótico general a sistemas biológicos, la información será, en la mayoría de los casos, un proceso dependiente del intérprete. No puede ser disociada de un agente comunicativo (potencial o efectivo) situado (y activamente distribuido). Él es dependiente del intérprete en el sentido de que la información conecta triádicamente la representación (signo), el objeto, y un efecto (interpretante) sobre el intérprete (que puede ser un organismo o parte de un organismo). En un sistema biológico, la información depende tanto del intérprete como del objeto (en el cual la forma comunicada en la información se halla incorporada como factor restrictivo del proceso interpretativo).

Así, puede construirse un marco para pensar sobre información como un proceso en términos peirceanos, mediante el empleo de las siguientes definiciones:

[Información $=$ semiosis] Proceso inherentemente triádico a través del cual una forma incorporada en el objeto de modo regular, es comunicada a un interpretante a través de la mediación de un signo.

[Información potencial $=$ semiosis potencial] Proceso de comunicación de una forma de un objeto a un interpretante a través de la mediación de un signo, que tiene una disposición para realizarse en un momento determinado.

[Información efectiva $=$ semiosis efectiva] Proceso por el cual un signo produce realmente un efecto (interpretante) en algún sistema (un intérprete) haciendo que el interpretante esté en relación con el mismo objeto (el objeto del signo) al que el propio signo representa. Por lo tanto, el signo media la relación entre el objeto y el interpretante y, de este modo, el signo comunica efectivamente una forma del objeto al interpretante, cambiando el estado del intérprete.

\section{Semiótica aplicada: un análisis semiótico de los genes y la información genética}

En el sistema de información genética, la síntesis de proteínas y ARNs se relaciona con el ácido desoxirribonucleico (ADN). Regiones específicas de esta molécula actúan como 'moldes' para la 'trascripción' de ácidos ribonucleicos (ARNs) a través de un complejo multiproteico, que incluye la ARN polimerasa. Entre los ARNs, la ARN mensajera (ARNm) actúa como 'molde' para la síntesis de proteínas en el citoplasma. El ADN puede actuar como 'molde' para la síntesis de ARN gracias al apareamiento específico de bases de nucleótidos, los monómeros que constituyen los ácidos nucleicos, y el ARN, a su vez, puede actuar como 'molde' para la síntesis de proteínas gracias a las relaciones especificas entre secuencias de tres nucleótidos (los "codones") y aminoácidos, los monómeros de las proteínas. El conjunto de estas relaciones integra el 'código' genético (que existe en varias versiones ligeramente diferentes).

Los efectos de un gen codificador de proteínas en una célula u organismo dado son regulados principalmente por el control de la expresión genética al nivel de la iniciación de la trascripción. Este proceso de regulación resulta en el hecho de que sólo un subconjunto de todos los genes presentes en cualquier tipo de célula de un organismo pluricelular es realmente expresado.

El proceso por el cual la secuencia de nucleótidos de ARNm sirve como molde para la síntesis de proteínas es llamado 'traducción', y constituye una parte esencial de la síntesis de proteínas. Las ARNs mensajeras son a menudo llamadas de 'vehículos' de la 'información' genética transcrita del ADN. El 'mensaje' en juego es 'escrito' en forma de series de 'codones', cada uno de los cuales especifica un aminoácido en particular. Otra clase de moléculas de ARN, los ARN de transferencia (ARNt), desempeñan un papel fundamental en el proceso de 'descifrar' los codones en el ARNm. Cada tipo de aminoácido tiene su propio subconjunto de ARNts. Los ARNts actúan como transportadores específicos, ligando aminoácidos y trasladándolos a la extremidad en crecimiento de una cadena de polipéptidos en respuesta a codones específicos en el ARNm. La razón por la cual la ARNt correcta junto con el aminoácido correspondiente son seleccionados en cada paso en la síntesis de proteínas 
radica en el hecho de que cada molécula de ARNt específica contiene una secuencia de tres nucleótidos, llamada un 'anticodón', cuyas bases son pareadas a las bases del codón complementario en el ARNm.

A su vez, la relación específica entre ARNts y aminoácidos resulta de la ligación del aminoácido apropiado a un ARNt en una reacción catalizada por una aminoacil-ARNt sintetasa específica. La especificidad de la ligación entre los aminoácidos y los ARNts resulta de la capacidad de cada una de estas enzimas para reconocer un aminoácido y todos sus ARNts compatibles, o 'cognatos'. Por lo tanto, las reglas expresas en el código genético dependen, en última instancia, de la actividad de reconocimiento de aminoacil-ARNt sintetasas.

Si ahora revisamos los términos presentados entre comillas en los párrafos anteriores, podremos observar al lenguaje de la información en acción. Nuestra estrategia fue la de utilizar términos empleados frecuentemente de modo similar en documentos y libros sobre biología, a fin de destacar la importancia de construir una teoría para dar un significado preciso a este lenguaje predominantemente metafórico. Como mencionamos anteriormente, Griffiths señala que la información genética es una metáfora en búsqueda de una teoría (Griffiths 2001). Un análisis de los manuales de biología molecular (Pitombo, Almeida \& El-Hani 2008) demuestra que esto es realmente así, considerando que ningún concepto de 'información' teóricamente consistente (que esté más allá de la idea de información secuencial en los ácidos nucleicos o proteínas) es ofrecido en los mismos como base para comprender el lenguaje de la información que ellos utilizan.

Después de esta contextualización básica para la comprensión del sistema de información genética, podemos pasar a un análisis de los genes y de la información genética basada en la teoría de los signos de Peirce (Queiroz, Emmeche \& El-Hani 2005, El-Hani, Queiroz \& Emmeche 2006). Desde la perspectiva de esta teoría, la acción de un gen como signo debe ser entendida como una relación entre tres elementos (Figura 2). Al emplear la definición de 'información' presentada anteriormente, la información genética puede ser definida como un proceso semiótico. Desde esta perspectiva, hay mucho más en la información genética que simplemente una secuencia de nucleótidos de un tramo de ADN. Esta es una conclusión importante, dado que va contra el tratamiento de la información genética como una mera secuencia de información en el ADN o en las proteínas, y porque indica un camino diferente para conceptualizar la información en una teoría de la información biológica basada en la semiótica de Peirce.

En la Figura 2, una secuencia de nucleótidos en el ADN no es tratada como información en sí misma, sino como el primer correlato de la información interpretada como semiosis, es decir, un signo. Signos en el ADN son transcriptos en signos en ARNm procesados, con o sin la ocurrencia de splicing alternativo, un proceso a través del cual distintos patrones de procesamiento de ARN dan lugar a una serie de diferentes moléculas de ARNm procesado, cada una codificando proteínas diferentes, aunque relacionadas (isoformas). Si se verifica la ocurrencia de splicing alternativo, entonces un signo en el ADN será usado para producir diferentes signos en ARNm. El objeto inmediato de un gen como signo del ADN es la secuencia de aminoácidos o nucleótidos representados en el mismo. Y como diferentes objetos inmediatos pueden ser representados en el ADN (a través de procesos tales como el splicing alternativo), hay un espectro de interpretabilidad de un signo en el ADN, que es su interpretante inmediato.

Un gen codificador de proteínas, por ejemplo, sólo puede tornarse un signo en acción efectiva en una célula al representar -en una relación triádica- una secuencia específica de aminoácidos (objeto inmediato) a través de un proceso de reconstrucción de una forma específica (interpretante). ¿Qué es la información genética en este esquema? Ella puede ser entendida como todo el proceso a través del cual un gen actúa como signo en una célula determinada, mediando la reconstrucción de una secuencia específica de aminoácidos. La información es la relación triádica per se; un proceso, no algo que se encuentra en el primer correlato de este proceso, un signo en el ADN. En los signos en el ADN, sólo se encuentra información en potencia. Cuando esta información potencial se convierte en información actualizada, la misma no se halla contenida en los signos en el ADN aisladamente, sino que constituye el mismo proceso a través del cual actúan los signos. 


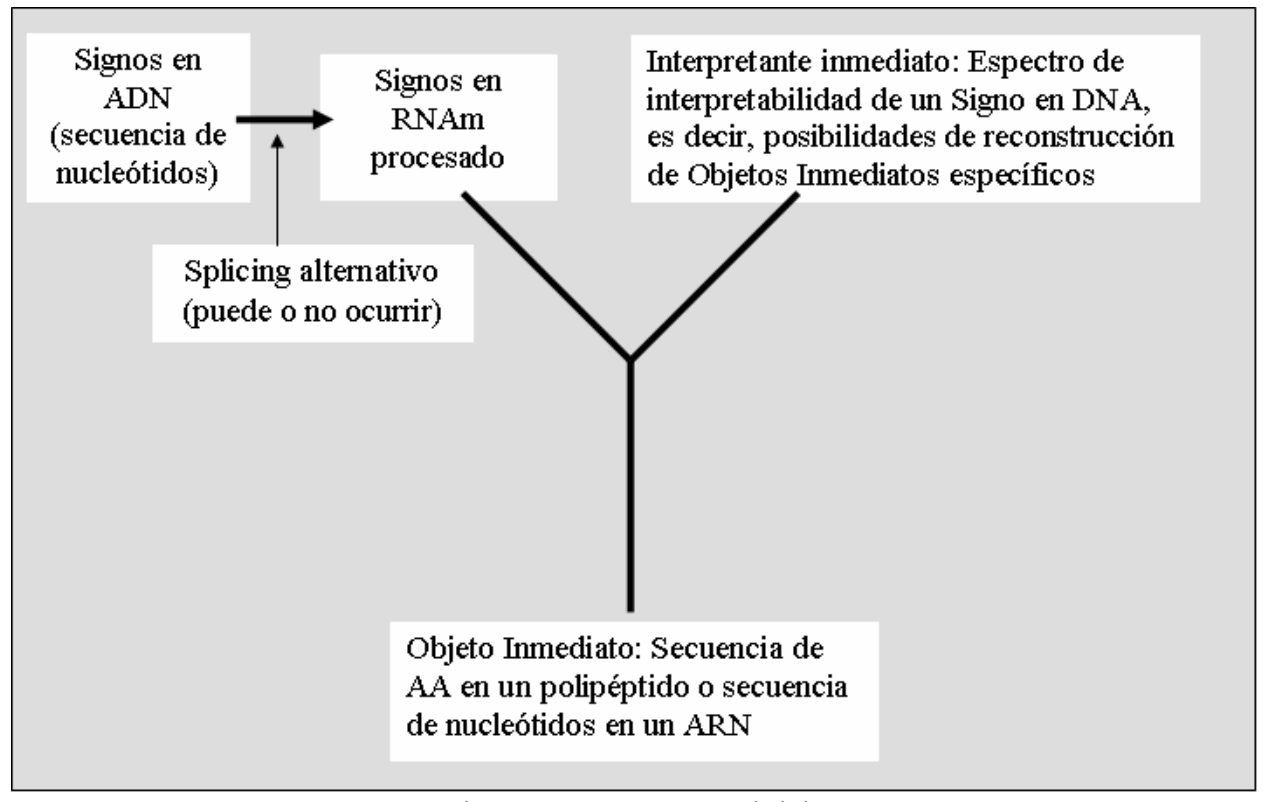

Figura 2: Un análisis semiótico general del gen como signo.

Un signo es el elemento mediador en un proceso semiótico a través del cual una forma es comunicada de un objeto a un interpretante. Esta es la razón por la cual aquí consideramos al interpretante como la reconstrucción de una forma (hábito) incorporada (embodied) en un objeto. 'Reconstrucción' alude en este caso a un proceso mediante el cual la forma de una proteína en una determinada generación celular es comunicada a través de signos en el ADN (en potencia) a la forma de una proteína en la generación siguiente de células. Así pues, se obtiene una regularidad en la estructura tridimensional y función de proteínas a través de las generaciones.

La relación entre signos en el ADN y las secuencias de aminoácidos en las proteínas es establecida mediante un complejo mecanismo de interpretación, que involucra trascripción, procesamiento de ARN y traducción. ${ }^{6}$ Por lo tanto, se requiere más de un sistema interpretativo para interpretar un segmento de ADN, incluyendo, por ejemplo, polimerasas de ARN, que participan en la trascripción de ADN a ARN, y ribosomas, responsables por la traducción de ARNm en proteínas. Estos sistemas interpretativos son partes o subsistemas de la célula como un intérprete global, y sus acciones están subordinadas a ella. La idea que la célula puede considerarse un intérprete global, al cual están subordinados una serie de subsistemas interpretativos dentro del sistema de información genética, ha sido dramáticamente reforzada por recientes análisis de la organización funcional de proteomas.

Considere, por ejemplo, que los sistemas celulares de múltiples componentes implicados en la trascripción, en el procesamiento y transporte de ARN no constituyen una simple línea de montaje, sino una compleja y extensa red en la que los signos circulan de modo no lineal, involucrando varios circuitos de retroalimentación (Maniatis \& Reed 2002, Kornblihtt et al. 2004). Es esta estructura de red la que hace posible la coordinación de los subsistemas interpretativos en el sistema de información genética de la célula. Por lo tanto, es claro que no podemos pasar fácilmente de los modelos a nivel celular a los modelos a nivel molecular en cuanto ponderamos sobre cual sistema es el que interpreta a los genes como signos. Los últimos avances en la comprensión de los sistemas celulares dejan cada vez más claro que cuando un gen es interpretado, el proceso de interpretación tiene lugar efectivamente a nivel celular, a pesar de que múltiples subsistemas moleculares son necesarios para esta tarea.

Esta idea de que, en última instancia, la célula en su totalidad participa en la red necesaria para la interpretación que se requiere para que tenga lugar el efecto del producto genético (Emmeche \& Hoffmeyer 1991, Pardini \& Guimarães 1992) es apoyada también por el papel de un impresionante

\footnotetext{
${ }^{6}$ Un modelo semiótico detallado de la trascripción y la traducción es presentado por El-Hani, Queiroz \& Emmeche (2006).
} 
conjunto de vías de señalización que regulan la interpretación de los signos de ADN. Como resume Fogle, "la acción y función del ADN se tornan significativas en el contexto de un sistema celular. La codificación de la información en el ADN es necesaria, pero no suficiente para el funcionamiento de los sistemas vivos" (Fogle 2000, p. 19).

De modo similar, el abordaje Peirceano de los genes y de la información genética implica que las estructuras genéticas no deben considerarse aisladamente del sistema más amplio por el cual son interpretadas. Desde esta perspectiva, el significado de un gen para su intérprete, la célula, o, en otras palabras, la significación biológica de un gen, no solo se encuentra en las secuencias de ADN de un cromosoma. La tesis de que la información genética involucra mucho más que tan sólo una secuencia de nucleótidos de ADN significa que deberemos incluir en nuestros modelos de información el efecto del gen-como-signo sobre la célula u organismo, y, de hecho, el propio rol de los subsistemas celulares como intérpretes de los segmentos de $\mathrm{ADN}$, de manera tal que ellos relacionan signos a objetos dinámicos específicos, proteínas que cumplen una función dentro del sistema celular y tienen un efecto sobre él, o sobre el organismo del cual la célula es parte.

En un marco peirceano, dejamos de lado la identificación de la información genética con la información secuencial en el ADN y nos movemos en dirección a su comprensión como un proceso semiótico. Como modo de subrayar la diferencia entre un abordaje de la información como proceso y otras explicaciones más habituales sobre lo que es la información, consideremos, por ejemplo, el argumento de Maynard Smith y Szathmáry de que la información es 'ese algo' que se conserva a lo largo de una serie de cambios en el medio material subyacente a un proceso de comunicación (Maynard Smith \& Szathmáry 1999, pp. 9-10).

Según el modelo desarrollado anteriormente, 'ese algo' conservado no es información, sino más bien la permanencia de una cierta relación en la forma reconstruida. La información es más bien el proceso por el cual una forma es comunicada a través de diferentes medios (signos), de modo que una estructura relacional se conserva a lo largo de todo el proceso, a pesar de que los aspectos significativos de la forma del objeto son continuamente reconstruidos. Aplicando esta idea en el marco del análisis ofrecido en esta sección, no es la información genética la que es conservada a través de las diferentes moléculas de ADN particulares (diferentes medios materiales) en diferentes organismos y generaciones, sino más bien una estructura relacional en la forma reconstruida, esto es, un hábito o tendencia a construir particulares del mismo tipo sobre la base de los signos disponibles en el ADN. Estos signos sólo pueden abrigar información potencial. En sí misma, la información genética es el proceso por el cual una estructura relacional es comunicada para una nueva proteína particular, es decir, todo el proceso a través del cual los genes como signos del ADN (implicando la potencialidad de la información genética como proceso) están irreductiblemente relacionados a objetos e interpretantes.

En términos semióticos, podemos comprender la trascripción, el procesamiento de ARN y la síntesis de proteínas como procesos de actualización de signos potenciales en genes codificadores de proteínas. Cuando entra en acción, un gen codificador de proteínas se convierte en parte de la semiosis efectiva, un proceso triádico por medio del cual el gen como signo indica un producto funcional determinado, sintetizado después del splicing, la edición de ARNm, o cualquier otra complejidad involucrada en la vía desde un tramo de ADN hasta la proteína. Este producto funcional tiene a su vez, un efecto sobre el organismo en el cual se expresa (su interpretante final), participando en las interacciones adaptativas con su entorno, y, de este modo, contribuyendo a la presencia en alta frecuencia de esos signos potenciales en la próxima generación. Notemos que no proponemos una inversión del dogma central (como si las secuencias de aminoácidos en las proteínas pudieran determinar las secuencias de nucleótidos en el ADN). Más bien, nos referimos al efecto de proteínas funcionales ante la probabilidad de que determinados genes, determinados signos mediadores del proceso de su síntesis, estarán presentes en generaciones futuras.

La actualización de un gen depende de las condiciones establecidas por una red semiótica de nivel superior, una red de procesos de señalización que regulan la expresión genética, determinando, en última instancia, la probabilidad de trascripción de un determinado gen, o el splicing de un dado preARNm de acuerdo con un patrón determinado, o la modificación química de determinada proteína de 
una manera tal que modula su función de un modo particular (por ejemplo, mediante fosforilación), y así sucesivamente. Por lo tanto, una variedad de mecanismos de regulación estudiados en la biología celular y molecular pueden ser comprendidos como integrantes de un ambiente macro-semiótico que establece las condiciones de contorno (boundary conditions) que determinarán de modo descendiente qué genes potenciales de un segmento de ADN serán actualizados, entrando en acción efectiva en una célula.

Esto muestra cómo diferentes complejidades involucradas en la expresión genética pueden ser introducidas en nuestro análisis: condiciones de contorno establecidas por este ambiente macrosemiótico determinarán, por ejemplo, qué tramo de ADN será leído (permitiendo por ejemplo un análisis de la trascripción de genes superpuestos o anidados), qué patrón de splicing o edición de ARN será realizado de manera en que va a producir una determinada ARNm procesada (permitiendo tener en cuenta las sutilezas del splicing alternativo o de la edición del ARN), qué proteína funcional será efectivamente construida por la célula (permitiendo considerar las modificaciones químicas y/o estructurales sufridas por la secuencia primaria de aminoácidos de una proteína), y así sucesivamente. La influencia reguladora del nivel macro-semiótico, es decir, de la red de procesos de señalización, sobre los subsistemas interpretativos, y, por lo tanto, sobre la trascripción, el splicing, la traducción, muestra que en última instancia debemos considerar a la célula en su totalidad como participante de la red necesaria para la actualización de genes potenciales en el ADN.

La red celular de procesos semióticos es, a su vez, muy sensible a factores ambientales, dada la naturaleza semi-abierta de los sistemas vivos. En consecuencia, los genes, como signos potenciales en el ADN, son actualizados a través de disposiciones reguladoras derivadas de una red de vías de señalización que resultan en respuestas celulares específicas a otros signos derivados de una jerarquía de 'contextos', 'ambientes', o, en nuestros propios términos, niveles semióticos que pueden dirigir la expresión genética (es decir, establecer condiciones de contorno para la selección de los genes potenciales en el $\mathrm{ADN}$ ), que van desde los sistemas de interacción gen-gen a organismos, pasando por el núcleo, el citoplasma, la célula, la superficie celular, la matriz extracelular, los campos morfogenéticos, las condensaciones colectivas de células (blastemas), los órganos, etc. (ver, por ejemplo, Hall 2001).

De este modo, la célula, como intérprete, responde a señales o signos del ambiente por medio de una alteración especifica de sus estados internos, provocados por toda una red de transducción de signos que culmina en un cambio en algún nivel de la regulación genética. (Para un análisis semiótico de los sistemas de transducción de signos, ver Bruni 2003, Queiroz \& El-Hani 2006b, El-Hani, Arnellos \& Queiroz 2007.) Estas relaciones no pueden comprenderse tan sólo en términos de interacciones moleculares que se producen en las redes de transducción de signos, ya que este último proceso implica fundamentalmente eventos semióticos, como sugiere claramente el uso generalizado del lenguaje de la información en la modelización y explicación de vías de señalización.

Este análisis semiótico nos permite ofrecer un interesante abordaje de la 'transmisión' de información. No es información efectiva la que está siendo comunicada cuando uno observa por ejemplo, la 'transmisión vertical' de una generación parental a su progenie. Desde la perspectiva del modelo desarrollado anteriormente, lo que está siendo comunicado es tan solo información potencial, esto es, la potencialidad de un proceso llamado información. Sólo se puede decir, como ya hemos explicado, que la información potencial (mas no la efectiva) es cargada por tramos de ADN. Signos en el ADN sólo se convertirán en elementos de la información efectiva cuando sean interpretados por la célula. La información efectiva no puede ser transportada de un sistema a otro en sí misma, sino que tan solo la información potencial puede ser cargada por el primer correlato de las tríadas, signos (cuyos vehículos en sistemas biológicos son típicamente entidades físico-químicas).

Este análisis biosemiótico del sistema de información genética conduce, pues, a las siguientes conclusiones: (i) Los genes deben ser tratados como signos en el ADN, que pueden tener efecto sobre una célula únicamente a través de un proceso triádico, la semiosis; (ii) Este proceso es la información genética e involucra más que a los genes solamente, sino también a objetos y a interpretantes; (iii) La información genética es el proceso mediante el cual una forma en un objeto dinámico (una proteína 
funcional) es comunicada a un interpretante (la reconstrucción de una secuencia específica de aminoácidos de una célula) a través de signos en el ADN.

\section{Consideraciones finales}

El marco para la construcción de una teoría de la información biológica presentado aquí es coherente con la idea general de la información genética y los procesos de señalización en la genética y la biología molecular, con la diferencia fundamental de que, en primer lugar, un concepto de información es explícitamente formulado dentro de un marco teórico heurísticamente poderoso, y en segundo lugar, sobre esta base, la información es conceptualizada como un proceso. En nuestro entendimiento, es éste un fructífero camino a seguir con el fin de construir un marco para la biología que resulte más compatible con la naturaleza cada vez más compleja y dinámica de los sistemas biológicos, puesta de manifiesto por los recientes avances en las ciencias biológicas (para algunas sugerencias en esta misma dirección, ver, por ejemplo, Neumann-Held 2001, Keller 2005).

Hemos sostenido que el modelo semiótico es una contraparte necesaria a los modelos funcionales y mecanísticos de los sistemas genéticos y de señalización. Las herramientas conceptuales y metodológicas que ofrece la semiótica de Peirce pueden ayudar a definir con mayor precisión lo que constituye la información en los sistemas biológicos. Esto es particularmente importante en una época en la que la biología se considera cada vez más como una ciencia de la información. Siempre es útil recordar que actualmente no tenemos una noción general establecida sobre la información biológica (a pesar del papel que el concepto de información no-semántica ofrecido por la teoría matemática de la comunicación puede desempeñar en la investigación biológica). Es una propuesta básica de este trabajo que la biosemiótica pueda ayudar en la construcción de un concepto semántico/pragmático de la información biológica.

Bibliografía

Adami, C. (2004), "Information Theory in Molecular Biology”, Physics of Life Reviews 1: 3-22.

Bergman, M. (2000), "Reflections on the Role of the Communicative Sign in Semeiotic", Transactions of the Charles S. Peirce Society: A Quarterly Journal in American Philosophy 36(2): 225-254.

Bruni, L. E. (2003), A Sign-theoretic Approach to Biotechnology, Unpublished Ph.D. dissertation. Institute of Molecular Biology, University of Copenhagen.

Colapietro, V. (1989), Peirce's Approach to the Self: A Semiotic Perspective on Human Subjectivity, New York: State University of New York Press.

Cover, T. M. y J. A. Thomas (1999), “Information Theory”, en Wilson, R. A. y F. C. Keil (eds.), The MIT Encyclopedia of the Cognitive Sciences, Cambridge, MA: MIT Press, pp. 404-406.

Deacon, T. (1997), The Symbolic Species: The Co-evolution of Language and the Brain, New York: W. W. Norton \& Company.

Debrock, G. (1996), "Information and the Metaphysical Status of the Sign”, en Colapietro, V. y T. Olshewsky (eds.), Peirce's Doctrine of Signs - Theory, Applications, and Connections, Berlin/New York: Mouton de Gruyter, pp. 80-89.

De Tienne, A. (2003), “Learning qua Semiosis", S.E.E.D. Journal (Semiotics, Evolution, Energy, and Development) 3(3): 37 53.

El-Hani, C. N. (1997), “Explicações causais do desenvolvimento: são os genes suficientes?”, Cadernos de História e Filosofia da Ciência, série 3, 7(1): 121-167.

El-Hani, C. N. y C. Emmeche (2000), “On Some Theoretical Grounds for an Organism-centered Biology: Property Emergence, Supervenience, and Downward Causation”, Theory in Biosciences 119: 234-275.

El-Hani, C. N. y J. Queiroz (2005), “Downward Determination”, Abstracta 1(2): 162-192. 
El-Hani, C. N., Queiroz, J. y C. Emmeche (2006), “A Semiotic Analysis of the Genetic Information System”, Semiotica 160(1-4): 1-68.

El-Hani, C. N., Argyris, A. y J. Queiroz (2007), "Modeling a Semiotic Process in the Immune System: Signal Transduction in B-cells Activation”, TripleC [Cognition, Communication, Co-operation] 5(2): 24-36.

Emmeche, C. (1994), "The Computational Notion of Life”, Theoria - Segunda Época 9(21): 1-30.

Emmeche, C. y J. Hoffmeyer (1991), "From Language to Nature - The Semiotic Metaphor in Biology", Semiotica 84(1/2): $1-42$.

Emmeche, C., Køppe, S. y F. Stjernfelt (2000), “Levels, Emergence and Three Versions of Downward Causation”, en Andersen, P. B., Emmeche, C., Finnemann, N. O. y P. V. Christiansen (eds.), Downward Causation: Minds, Bodies and Matter, Aarhus: Aarhus University Press, pp. 13-34.

Fetzer, J. H. (1997), “Thinking and Computing: Computers as Special Kinds of Signs”, Minds and Machines 7: 345-364.

Fitzgerald, J. (1966), Peirce's Theory of Signs as Foundation for Pragmatism, University of Notre Dame: Mouton \& Co.

Fogle, T. (2000), “The Dissolution of Protein Coding Genes”, en Beurton, P. J., Falk, R. y H.-J. Rheinberger (eds.), The Concept of the Gene in Development and Evolution, Cambridge: Cambridge University Press, pp. 3-25.

Freadman, A. (2004), The Machinery of Talk: Charles Peirce and the Sign Hypothesis, Stanford: Stanford University Press.

Freeman, E. (1983), The Relevance of Charles Peirce, La Salle, IL: Monist Library of Philosophy.

Gomes, A., El-Hani, C. N., Gudwin, R. y J. Queiroz (2007), “Towards the Emergence of Meaning Processes in Computers from Peircean Semiotics”, Mind EF Society - Cognitive Studies in Economics and Social Sciences 6(2): 173. 187.

Griffiths, P. E. (2001), "Genetic Information: A Metaphor in Search of a Theory”, Philosophy of Science 68(3): $394-403$.

Hall, B. K. (2001), “The Gene is not Dead, merely Orphaned and Seeking a Home”, Evolution and Development 3(4): 225-228.

Hoffmeyer, J. (1996), Signs of Meaning in the Universe, Bloomington \& Indianapolis: Indiana University Press.

Hookway, C. (1985), Peirce, London: Routledge \& Kegan Paul.

Hookway, C. (2002), Truth, Rationality, and Pragmatism: Themes from Peirce, Oxford: Oxford University Press.

Houser, N. (1997), "Introduction: Peirce as a logician”, en Houser, N., Roberts, D. y J. Evra (eds.), Studies in the Logic of Charles Sanders Peirce, Bloomington and Indianapolis: Indiana University Press, pp. 1-22.

Hulswit, M. (2001), "Semiotic and the Cement of the Universe: A Peircean Process Approach to Causation", Transactions of the Charles S. Peirce Society 37(3): 339-363.

Ideker, T., Galitski, T. y L. Hood (2001), “A New Approach to Decoding Life: Systems Biology”, Annual Review of Genomics and Human Genetics 2: 343-372.

Jablonka, E. (2002), “Information: Its Interpretation, its Inheritance, and its Sharing”, Philosophy of Science 69: 578-605.

Jablonka, E. y M. J. Lamb (2005), Evolution in Four Dimensions: Genetic, Epigenetic, Behavioral, and Symbolic Variation in the History of Life, Cambridge, MA: MIT Press.

Johansen, J. D. (1993), Dialogic Semiosis, Bloomington and Indianapolis: Indiana University Press.

Keller, E. F. (2000), The Century of the Gene, Cambridge, MA: Harvard University Press.

Keller, E. F. (2005), “The Century beyond the Gene”, Journal of Biosciences 30: 3-10.

Kornblihtt, A. R., de la Mata, M., Fededa, J. P., Muñoz, M. J. y G. Nogues (2004), "Multiple Links between Transcription and Splicing", RNA 10: 1489-1498.

Lizska, J. J. (1990), "Peirce's Interpretant", Transactions of the Charles S. Peirce Society: A Quarterly Journal in American Philosophy, Summer, 26(1): 17-61.

Maniatis, T. y R. Reed (2002), “An Extensive Network of Coupling among Gene Expression Machines”, Nature 416: 499-506.

Marty, R. y A. Lang (1997), "76 Definitions of the Sign by C. S. Peirce Collected and Analyzed by C. S. Peirce, with an Appendix of 12 further Definitions or Equivalents proposed by A. Lang”, Arisbe Website, organizado por J. 
Ransdell. Disponible en: http://www.cspeirce.com/menu/library/rsources/76defs/76defs.htm. Acceso: 11 de enero de 2007.

Maynard Smith, J. y E. Szathmáry (1999), The Origins of Life: From the Birth of Life to the Origins of Language, Oxford: Oxford University Press.

Mayr, E. (1982), The Growth of Biological Thought: Diversity, Evolution, and Inheritance, Cambridge, MA: Harvard University Press.

Merrell, F. (1995), Peirce's Semiotics Now, Toronto: Canadian Scholar's Press.

Murphey, M. (1993), The Development of Peirce's Philosophy, Cambridge: Harvard University Press.

Neumann-Held, E. (2001), "Let's Talk about Genes: The Process Molecular Gene Concept and its Context”, en Oyama, S., Griffiths, P. E. y R. D. Gray (eds.), Cycles of Contingency: Developmental Systems and Evolution, Cambridge, MA: MIT Press, pp. 69-84.

Nijhout, H. F. (1990), "Metaphors and the Role of Genes in Development", Bioessays 12(9): 441-446.

Oyama, S. (2000), The Ontogeny of Information: Developmental Systems and Evolution, $2^{\mathrm{a}}$ ed. Cambridge: Cambridge University Press, $1^{\text {a }}$ ed. 1985.

Pardini, M. I. M. C. y R. C. Guimarães (1992), “A Systemic Concept of the Gene”, Genetics and Molecular Biology 15(3): 713-721.

Parker, K. (1998), The Continuity of Peirce's Thought, Nashville: Vanderbilt University Press.

Peirce, C. S. (1931-1935), The Collected Papers of Charles Sanders Peirce, edición electrónica reproduciendo los Vols. I-VI (Hartshorne, C. y P. Weiss (eds.), Cambridge, MA: Harvard University Press, 1931-1935) y VII-VIII (Burks, A. W. (ed.), Cambridge, MA: Harvard University Press, 1958), Charlottesville: Intelex Corporation.

Peirce, C. S. (1967), Annotated Catalogue of the Papers of Charles S. Peirce (ed. por R. Robin), Amherst, MA: University of Massachusetts.

Peirce, C. S. (1977), Semiotic and Significs: The Correspondence between Charles S. Peirce and Victoria Lady Welby (ed. por C. S. Hardwick), Bloomington: Indiana University Press.

Peirce, C. S. ([1893-1913] 1998), The Essential Peirce: Selected Philosophical Writings, Vol. II, Peirce Edition Project, Bloomington and Indianapolis: Indiana University Press.

Peirce, C. S. ([1839-1914] 1982-2000), Writings of Charles S. Peirce: a Chronological Edition, Vol. 2, Peirce Edition Project, Bloomington: Indiana University.

Pitombo, M. A., Almeida, A. M. R. de y C. N. El-Hani (2008), "Gene Concepts in Higher Education Cell and Molecular Biology Textbooks”, Science Education International 19(2): 219-234.

Potter, V. G. ([1967] 1997), Charles S. Peirce: On Norms $\mathcal{E}$ Ideals, New York: Fordham University Press (The University of Massachusetts Press).

Queiroz, J. y C. N. El-Hani (2006a), "Semiosis as an Emergent Process", Transactions of the Charles S. Peirce Society 42(1): 78-116.

Queiroz, J. y C. N. El-Hani (2006b), "Towards a Multi-level Approach to the Emergence of Meaning Processes in Living Systems", Acta Biotheoretica 54(3): 174-206.

Queiroz, J. y S. Ribeiro (2002), "The Biological Substrate of Icons, Indexes and Symbols in Animal Communication: A Neurosemiotic Analysis of Vervet Monkey Alarm-calls", en Shapiro, M. (ed.), The Peirce Seminar Papers 5, New York: Berghahn Books, pp. 69-78.

Queiroz, J., Emmeche, C. y C. N. El-Hani (2005), "Information and Semiosis in Living Systems: A Semiotic Approach", S.E.E.D. Journal (Semiotics, Evolution, Energy, and Development) 5(1): 60-90.

Ransdell, J. (1977), “Some Leadings Ideas of Peirce's Semiotic”, Semiotica 19(3/4): 157-178.

Ribeiro, S., Loula, Â., Araújo, I., Gudwin, R. y J. Queiroz (2007), "Symbols Are not Uniquely Human”, Biosystems 90: 263-272.

Santaella-Braga, L. (1994), "Peirce's Broad Concept of Mind”, European Journal for Semiotic Studies 6(3/4): 399-411. 
Sarkar, S. (1996), "Biological Information: A Skeptical Look at Some Central Dogmas of Molecular Biology”, en Sarkar, S. (ed.), The Philosophy and History of Molecular Biology: New Perspectives, Dordrecht: Kluwer, pp. 187-231.

Savan, D. (1987-1988), An Introduction to C. S. Peirce's Full System of Semeiotic, Toronto Semiotic Circle, Monograph Series of the TSC, Number 1.

Shannon, C. E. y W. Weaver (1949), The Mathematical Theory of Communication, Urbana, IL: University of Illinois Press.

Short, T. (1996), “Interpreting Peirce's Interpretant: A Response to Lalor, Liszka, and Meyers", Transactions of the Charles S. Peirce Society: A Quarterly Journal in American Philosophy 32(4): 488-541.

Stuart, C. I. J. M. (1985), “Bio-informational Equivalence”, Journal of Theoretical Biology 113: 611-636.

Tiercelin, C. (1995), “The Relevance of Peirce's Semiotic for Contemporary Issues in Cognitive Science”, en Haaparanta, L. y S. Heinamaa (eds.), Mind and Cognition: Philosophical Perspectives on Cognitive Science and Artificial Intelligence (= Acta Philosophica Fennica 58: 37-74).

Weiss, P. y A. W. Burks (1945), “Peirce’s Sixty-Six Signs”, The Journal of Philosophy 42: 383-388.

Williams, N. (1997), "Biologists Cut Reductionist Approach Down to Size”, Science 277(5325): 476-477. 